\title{
The pursuit of beauty: the enforcement of aesthetics or a freely adopted lifestyle?
}

Henri Wijsbek Erasmus University, Rotterdam, the Netherlands

\begin{abstract}
Facelifts, tummy tucks and breast enlargements are no longer the privilege of the rich and the famous. Any woman can have all these and many more cosmetic surgical treatments, and an increasing number of women do. Are they having cosmetic surgery because they are duped by a male-dominated beauty system, or do they genuinely choose these operations themselves? Feminists (and others) give diametrically opposed answers to this question. At the heart of the controversy, or so I claim in this article, lies a conceptual problem about free choice; therefore, the only thing that can settle it is a conceptual analysis of "freedom". After having briefly outlined the views of both sides of the debate, I offer such an analysis. (Fournal of Medical Ethics 2000;26:454-458)
\end{abstract}

Keywords: Cosmetic surgery; lifestyle; free choice; coercion

\section{Introduction}

Considering the amount of time, money and effort some people spend on clothes, cosmetics and their looks in general, the pursuit of beauty is a lifestyle if anything is. One feminist aptly calls it "a deeply significant existential project"1 ; not a bad definition of "lifestyle" actually. We take an enormous interest in the way our body looks: we paint and pierce it, we keep it in shape through exercise and diet, and we take it to the cosmetic surgeon if we're really dissatisfied with some specific part of it. People do go to considerable lengths and are willing to incur serious risks, to change the appearance of their bodies for what they take to be the better.

Concern about their looks guides people's lives. So in one important sense the pursuit of beauty is clearly a lifestyle. But paradigmatically, in order to qualify as a lifestyle, a way of life should also be something you have chosen yourself. A lifestyle is a way of showing the world which things in life you deem important, what kind of life you want to live, what kind of person you want to be. This goes for men as well as for women. But the massive pressure on women to live up to some ideal standard of beauty, makes it particularly doubtful whether women's choices concerning appearance are anything but mere reflections of fashion, or worse still, of male-dominated power relations. Can women's pursuit of youth and beauty, then, ever really qualify as a freely adopted lifestyle?

\section{Morgan and the technological beauty imperative}

At least one feminist answers the last question with a resounding "No"! In an article entitled "Women and the knife: cosmetic surgery and the colonization of women's bodies", Kathryn Pauly Morgan sets out to investigate whether cosmetic surgery is liberating or coercive. As the title suggests, she has no doubts about the outcome. What makes her article interesting therefore, is rather what makes her think that, despite appearances to the contrary, women are coerced into cosmetic surgery. The key to her answer lies in what she calls "paradoxes of choice" that is, situations that leave women no real options at all. She distinguishes three such paradoxes.

The first is the paradox of conformity: women do not use the medical technology to underscore their uniqueness or eccentricity, rather they all let the one and the same "Baywatch" standard determine their looks. "More often than not, what appear at first glance to be instances of choice turn out to be instances of conformity."

Secondly, women who involve themselves in the pursuit of youth and beauty do not take their body as something natural or given, but rather as raw material to be shaped and pruned to fit some external standard. Their bodies are transformed for others to exploit them. And it is men who are wielding the power, either actual men or merely imagined men who occupy the consciousness of women and make them into self-surveying subjects. This is the paradox of colonisation. It looks as if women are cultivating their own bodies, whereas in fact their bodies are being colonised by men.

Finally, there is an overwhelming pressure to undergo cosmetic surgery. The technological beauty imperative enforces itself in numerous ways: through advertising, articles in the media, in so-called success stories, in Miss America pageants. At the same time, the beauty imperative sets a new norm: those who refuse to submit to it will become stigmatised. What used to be normal is rapidly becoming deviant, problematic, inadequate and deformed. Eventually, Morgan ventures, "the 'ordinary' will come to be perceived and evaluated as the "ugly"'. ${ }^{2}$ The fact that women are coerced to avail themselves of these techniques and the ensuing pathological inversion of the normal constitutes the third paradox, the paradox of coerced voluntariness and the technological imperative. 
Whenever a woman conforms to some single, external standard imposed on her, the conditions of genuine choice have not been met. If any of these paradoxes prevail therefore, she is not making a choice of her own, but is being forced to adapt herself to men's norms. Actually not just men's norms, nor just "white, western and Anglo-Saxon" norms, but norms that are "male-supremacist, racist, ageist, heterosexist, anti-Semitic, ableist and classbiased" and to be on the safe side, Morgan adds the ominous "eugenicist" as well. ${ }^{3}$

\section{Davis and the desire to be ordinary}

In her very interesting book, Reshaping the Female Body, Kathy Davis offers a totally different picture of cosmetic surgery and the partial freedom women enjoy to avail themselves of its mixed blessings. Davis has investigated the actual decision process of women contemplating undergoing cosmetic surgery. Typically, they take the step of consulting a cosmetic surgeon only after having pondered the decision for years. Often they seek support from a woman who has had cosmetic surgery herself, rarely from a husband or lover. Usually they have to overcome opposition, from friends, family and colleagues. All the women Davis talked with insisted they wanted the surgery for themselves. Interestingly, even women with very bad side effects and permanent disfigurement were happy they had finally taken their lives into their own hands.

The women Davis spoke to, mostly women who had had their breasts augmented or reduced, invariably described years of suffering before even thinking about consulting a cosmetic surgeon. Their suffering, so convincingly rendered by Davis, had pervaded the whole of their lives: when buying clothes, when going to the beach, when doing sport, when having sex. They had been constantly reminded that their breasts were too big or too small.

One of the women, Sandra, complained that her breasts made her seem like somebody else: "Big breasts are supposed to be sexy. So you got to be a sex-bomb, whether you want or not". She spent years hiding her breasts under bulky sweaters and leather jackets, trying to avoid being reduced to "just a pair of tits". ${ }^{4}$ Ellen suffered from the opposite "problem". One story she tells is particularly poignant. She had just given birth to her first child and was lying in a hospital bed, on top of the world, feeling one hundred per cent woman. Then the nurse came in to sponge her off. She started washing Ellen's face, then her breasts, and she blurted out: "Gee, you're flat as a pancake, aren't you?" Even as she was telling this to Davis she began to cry. "It was like being stabbed with a knife; it was, it was so awful, just really awful".

Sandra and Ellen didn't want to become beautiful, they wanted to become ordinary. They wanted to put an end to their suffering, and cosmetic surgery had come to be the only way to achieve their goal.

In the last chapter of her book, Davis takes issue with Morgan about the nature of cosmetic surgery and the freedom of choice. Davis does not deny that there is pressure on women to have their bodies altered, but throughout her book she stresses women's agency. Cosmetic surgery is not simply imposed, it is fervently desired by its recipients. Women having cosmetic surgery are knowledgeable and responsible agents, no "more duped by the feminine beauty-system than women who do not see cosmetic surgery as a remedy to their problems with their appearance". ${ }^{6}$ At the same time, she regrets the fact that women are willing to undergo risky operations. She wishes that circumstances would be otherwise and that women would choose a different course of action.

\section{The problem}

I find this controversy between Morgan and Davis fascinating. Who is right? And if either is, how can it be established which one? On the face of it, Davis's conclusions seem to be by far the more plausible. They are based on sound, empirical research, whereas Morgan has done little more by way of empirical investigation than skim a few glossy magazines featuring interviews with knife-happy surgical dopes. Moreover, Davis, somewhat to her own surprise and against her own will, comes up with a balanced, not to say ambiguous view of cosmetic surgery. She weighs the pros and cons carefully and draws a conclusion that is almost shocking to the feminist she considers herself to be, let alone to more orthodox feminists with whom she has indeed experienced some troubling and unpleasant confrontations because of her liberal outlook. In that sense, her book is open-minded and courageous. Morgan's article on the other hand, smacks of lopsided exaggeration. She knew all along what she thought about cosmetic surgery, and drives home the politically correct analysis with force once again.

I'm afraid, however, that the controversy cannot be so easily settled in favour of Davis. It is not at all an easy job to decide how the data should be interpreted. Morgan could acknowledge all of Davis's results and yet stick to her own theory. Women may well say or think they make their own choices, whereas in fact they are only doing what the sexist, anti-Semitic, ageist, etc, etc, system requires them to do. It is hard to see how this disagreement about the interpretation of the empirical data could be solved empirically.

One of Davis's main objectives is to find a way of being critical of a beauty-system that treats women as inferior, without blaming the women who partake in it. But how can she do so, while at the same time stressing women's agency? Her formula - own choice, bounded circumstances - is not very satisfactory, because choices are always made with less than complete information, under conditions not wholly of the agent's own making, and with few if any ideal options available. It seems to follow from her assumptions that women are blameable after all. How could anyone choose to partake in a blameable practice, without her- or himself incurring any blame? 
Actually, Morgan's views seem to be more condoning of women. If they do not choose to undergo cosmetic surgery, but are rather coerced into compliance by an oppressive beauty-system, they can hardly be blamed for being so coerced. It is the system that should be blamed, not its victims. But Morgan's views have some nasty implications as well. Not only are women victims, they are duped victims at that, surgical dopes, not real agents responsible for their own doings.

Underlying the disagreement between Morgan and Davis is a conceptual problem about freedom and responsibility. Before we can answer the question whether women who participate in the beautysystem are blameable agents or innocent zombies, or whether yet a third characterisation is more appropriate, we must become clear about the conditions of freedom, agency and blame.

\section{Freedom, agency and blame}

Neither Morgan nor Davis makes it very clear how the beauty-system actually sustains its coercive influence. Morgan has not empirically investigated the matter, but she makes two suggestions. In the first place, its evil influence is spread by men, "brothers, fathers, male lovers, male engineering students who taunt and harass their female counterparts, and by male cosmetic surgeons". And if not by actual men, then by "hypothetical men" who live "ghostly but powerful lives in the reflective awareness of women".

Davis, who has painstakingly investigated women's actual decision process, concludes that contrary to what is assumed by Morgan and many others, women are not pressed into the operation by actual men. As a matter of fact, husbands and boyfriends more often than not try to talk their partners out of it. For that reason, some women even concealed that they were planning to have an operation from their husbands or boyfriends. Actually, when Davis describes what makes women try cosmetic surgery as a last resort, other women figure prominently not only as support, but also as catalysts. Many of the painful remarks about their appearance were made by other women, either out of jealousy, or condescension or mere thoughtlessness. I have already mentioned the nurse's remark about Ellen, but Davis quotes some others as well, for instance: "Gosh, I thought you had more than that!" and "Big breasts are so-o-o uncomfortable dear. I wish I had yours".

However, Davis does think a considerable pressure is being exerted by something much more abstract and far less tangible than real men or women, something she calls "the beauty-system" or "the gender society", and sometimes still less specific "the social order", without elaborating on the content or working of this "social order". I suppose this is the same as what Morgan refers to when she uses the more picturesque phrase "hypothetical men". But according to Davis this pressure is not so strong as actually to coerce women into cosmetic surgery. They are left with a choice. Her formula for this ambiguous situation was: choice, constrained by circumstances which are not of the agent's own making. The constraints she refers to are the relative lack of information about the operation and its possible consequences and secondly, the lack of viable alternatives for women in a society organised by gender and power hierarchies.

Lack of information is something that is inherent in all choice situations. People do not have perfect foresight: some options are apt to be overlooked, and the ones considered can always turn out to be different from what was being imagined. Notoriously this holds for medical interventions. But only if the surgeon withholds available and relevant information on purpose could the situation be called coercive. In that case, women would be forced to make a decision on a skewed set of data. If this actually happens, they cannot make a free decision and therefore they cannot be held responsible for it. But this is hardly a controversial case. I take it that literally everybody agrees that the surgeon should give the woman all the relevant data. If he does not, he is to be blamed, not she.

The complaint about lack of viable options is much more difficult to deal with. What options are lacking, what circumstances should be different? I have no reliable figures, and they would be very hard to come by, but the number of women who do opt for cosmetic surgery is almost negligible compared to the number who do not. In order to make the claim that women have no viable options except cosmetic surgery at all plausible, the category of women to whom it applies has to be made much more precise. Suppose such a category could be defined: women with characteristics $a, b$ and $c$ all opt for cosmetic surgery under circumstances $\mathrm{x}, \mathrm{y}$ and $\mathrm{z}$. Even if this claim could be vindicated, nothing as yet would have been established as to what actually causes them to do so. Physical and psychological characteristics such as size of breasts and lack of self assurance would presumably figure on the one side, and stereotypes and role models are among the things that would figure on the other side of some such explanation.

\section{Causal explanation}

Suppose then that the statistically significant correlation could be dressed up to a causal explanation for this well-defined category of women, would that make them into the unfree and irresponsible zombies Morgan takes them to be? Not necessarily. Being caused to do something is not in itself a threat to either freedom or responsibility. It would only be so if you hold that free and responsible agency implies the ability to act in defiance of the causal network that makes up the rest of the world. It is a wildly implausible claim that people have such a contracausal metaphysical power and I have nothing to say to its credit. If you were to trace the antecedents of any act far enough, you would always find that its causes lie outside the agent. Usually acts are considered to flow from some combination of beliefs and desires. But of course one can always push the inquiry one step further back and ask where these beliefs and desires come 
from. Ultimately, they will be caused by something the person is not in control of. If being the ultimate cause of one's actions were a necessary condition for agency, nobody would ever be an agent.

According to a metaphysically less extraordinary view, agency is compatible with people being subject to all the laws that govern the rest of nature. A feeling of thirst normally causes me to try and quench it. I think I am very lucky to be caused to act in that way and I do not wish it were otherwise. The fact that I am caused to act in a certain way, does not imply that I must act in an insensible or mechanical way. I do not drink just anything; depending on further circumstances I take something hot or cold, sweet or bitter, alcoholic or nonalcoholic. And if I am attending a lecture, I wait until it is over before having my drink, because I think it would be ill-mannered to walk away in the middle of the lecture for such a reason. Normally, what I will actually do and when I will do it, is the outcome of my deliberation. As long as my acts are sensible responses to the requirements of the situation, as long as I am able to respond adequately to all its relevant features, I have all the freedom I can possibly wish. If these relevant features leave me no option but the right (or a right) one, that is no more a serious constraint on my freedom than the analogous constraint on belief formation would be. Our freedom would not be diminished if we were always caused to have only true beliefs.

\section{Best chances}

The way Davis describes the women who take recourse to cosmetic surgery, fits this picture very well. These women have a problem-an indisputable kind of suffering - they survey their options, and they pick that option that promises them the best chances to overcome their problem. They respond sensibly to the situation, make an intelligible decision and act accordingly. In particular, they don't expect the operation to work miracles, for instance that it will save a broken marriage. Admittedly, it is a somewhat risky option, but not an outrageously risky one. It seems therefore, that their decisions are based on a prudent cost-benefit analysis. What reasons could there be to call even this particular category of women innocent zombies and their decisions unfree or coerced? They do indeed seem to have all the characteristics of knowledgeable and responsible agents.

It might be countered that even if the "gender society" leaves women's capacity to reason instrumentally unimpaired, it distorts their capacity to form values to act on. Although I find this very hard to believe, it is conceivable that women or a category of women are manipulated in such a way that they are no longer able to discern which features of their lives really matter. In that case, they would be duped by magazines, advertisements and all the rest into putting beauty and appearance at the top of their preference-ordering. They would value beauty more than they should, spend more time and money on cosmetics than is proper and accord too little weight to other important things in life. To put it briefly, they would have become obsessed by their appearance, and obsession does not sit well with free agency.

But who can tell what the proper amount of attention is to pay to your appearance? Is lipstick $\mathrm{OK}$ ? Going to the hairdresser? Being choosy about the clothes you wear? Dieting? Fitness? Twice a week? Two hours a day? Everybody can come up with extreme examples of paying either too much or too little attention to appearance, but in between all causes are hard cases. And I think that is how it should be. All lifestyles can give rise to misgivings. Who can ever be sure she is not according too much importance in life to something not really worth it? How can you know that you would not be happier or lead a more satisfying life if you had chosen something completely different? To take up a lifestyle is to forsake other lifestyles that are equally worthy of being chosen. That is one of the reasons Morgan's description of the pursuit of beauty is such an appropriate definition of a lifestyle in general: it is "a deeply significant existential project", with all the meaningfulness and uncertainty that usually go with such projects.

After this, what is left of Morgan's three paradoxes? As to the first, women, except perhaps for a very small category of women, do not conform to a single standard. But even for this category, that fact in itself is no more significant than that a large number of Victorian men had whiskers or that nowadays some men practise body-building. Secondly, that this standard can be traced back to external influences is a property it shares with many, if not all, of our beliefs and desires. Finally, if you actually look at the decision process of these women, you will find that it forms a reasonable and adequate response to their problems and so is an expression of their freedom rather than an obstacle to it.

\section{Alternative explanation}

But even if women who have cosmetic surgery have all the characteristics of full-blown agents, the possibility is still left open that they are blameable agents, a possibility I took to be a consequence of Davis's position. That would be so if they knowingly and willingly were involving themselves in a morally reprehensible practice. Is cosmetic surgery reprehensible? According to Davis, the women who have cosmetic surgery do so in order not to be constantly looked at or made the object of offensive remarks, whether well meant or not; and they want to feel at ease in their own bodies. An alternative explanation would be that they want to look more beautiful. Both the ordinary and the beautiful are respectable and it is hardly blameworthy to strive for either.

If you want to become a proficient piano player, you must practise daily; if you write a scientific article, you don't expect the first draft to qualify as the final version; only with effort do we learn to become a good friend, parent, partner. Usually, to actualise values - be it artistic, scientific or moral 
values-is hard work. Why then should we have to accept our appearances as given?

\section{Lingering doubts}

Still, I can imagine that not everybody will be persuaded that women have a free choice in these matters. Given that circumstances are as they are, women are free to choose whether they want to have recourse to cosmetic surgery. To be free in a practical sense does not mean to be the uninfluenced originator of all your thoughts and actions; whoever fits that description is doomed to act in a haphazard and unintelligible way. Rather, it means to be able to respond adequately to the circumstances in which you find yourself. We want "a freedom within the world, not a freedom from it", in Susan Wolf's apt phrase. ${ }^{9}$

But sometimes we want the world to be different, rather than just to be able to respond adequately to the way it happens to be. Ideals of beauty and stereotypes differ from biological needs such as thirst, since they are not given in the same inescapable way. Different cultural ideals for women (and men) come and go, for example take fashion: slim in the twenties, buxom in the fifties. In a sense you could say these cultural ideals are made by human beings, albeit not in any direct or simple way. They would be very hard to influence for individuals, but perhaps governments or non-governmental organisations should do their utmost to change them. Or rather, to get rid of them altogether. After all, changing them would only change the category of women that could not live up to them and hence the category of women that would suffer from falling short of these ideals.

I suppose that this is what Davis meant when she said she wished circumstances could be different. Plastic surgery should not be an eligible way for women to overcome their problems with their appearance, because in Davis's ideal world, women would not have any problems with their appearance to begin with.

What would the world look like if Davis's wish were realised? It is very hard to imagine a world without such ever-changing beauty norms, but nevertheless, let me end with some speculations. It would be a world in which no woman ever suffered from the way she looked, because no woman, nor anybody else, would care about how she looked. Everybody would have become insensitive to aesthetic properties; nobody would be moved by Vermeer's Girl with the pearl or Schubert's Schöne Müllerin. There would be no poetry, only socialrealistic prose. It would be a paradise for pigs, and a boring place for people. In my view, that is too high a price to pay to get rid of cosmetic surgery.

Henri Wijsbek is a Research Fellow on a European Biomed project called Beauty and the Doctor, Department of Medical Ethics, Faculty of Medicine and the Health Sciences, Erasmus University, Rotterdam, the Netherlands.

\section{References}

1 Morgan KP. Women and the knife: cosmetic surgery and the colonization of women's bodies. Hypatia 1991;6:36.

2 See reference $1: 41$.

3 See reference $1: 36,38,42$.

4 Davis K. Reshaping the female body. The dilemma of cosmetic surgery. New York: Routledge, 1995: 77

5 See reference 4: 82

6 See reference 4: 163 .

7 See reference $1: 36,37$

8 See reference 4: 80, 82

9 Wolf S. Freedom within reason. New York: Oxford University Press, 1990: 93. I have benefited from this book in writing this paper. 